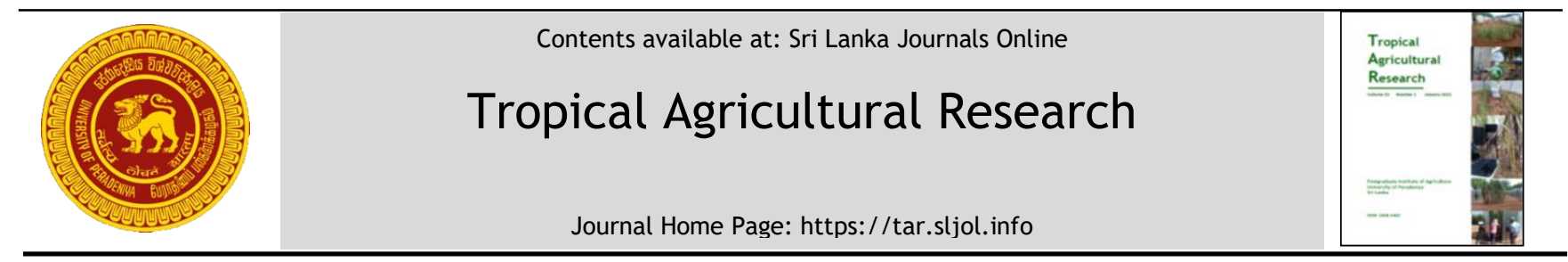

\title{
Soil Microorganisms Increase Mobility of Iron to Rice (Oryza sativa L.) Plants
}

\author{
W.S. Dandeniya $1^{1}$, Y.U.C. Wijerathna ${ }^{1}$, P.D.B.J. Palihakkara ${ }^{1}$ and Y.J.P.K. Mithrasena ${ }^{2}$ \\ ${ }_{1}^{1}$ Department of Soil Science, Faculty of Agriculture, University of Peradeniya, Peradeniya, 20400, Sri Lanka \\ ${ }^{2}$ Regional Rice Research and Development Center, Bombuwela, 12024, Sri Lanka
}

\section{ARTICLE INFO}

\section{Article history:}

Received: 6 April 2021

Revised version received: 28 July 2021

Accepted: 21 October 2021

Available online: 01 January 2022

\section{Keywords:}

Iron toxicity

Rhizosphere oxidizing power

Soil microorganisms

\section{Citation:}

Dandeniya, W.S., Wijerathna, Y.U.C., Palihakkara, P.D.B.J., and Mithrasena, Y.J.P.K. (2022). Cellulose decomposition potential of soil as affected by vegetable cultivation: A case study in Kegalle District, Sri Lanka. Tropical Agricultural Research, 33(1): 29-39.

DOI: http://doi.org/10.4038/tar.v33i1.8449

Dandeniya, W.S.

https://orcid.org/0000-0003-0795-3923

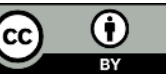

\section{ABSTRACT}

Understanding the mechanisms involved in iron (Fe) toxicity tolerance of rice would help to develop technologies to ensure maximum utilization of affected lands. This study was conducted to investigate whether soil microorganisms affect Fe uptake by rice plant and whether there are any varietal differences in relation to rhizosphere oxidizing powers. Three rice varieties with different Fe toxicity tolerance capacities were selected [BW 267-3 (tolerant), BW 363 (moderately tolerant) and BW 272-6b (susceptible)]. A pot experiment was conducted in a three-factor factorial design; soil with and without microorganisms, three Fe levels (2, 75 and $300 \mathrm{mg} / \mathrm{L})$ and three rice varieties. At 42 days after germination, dry matter yield and total Fe, K and $\mathrm{P}$ in shoots were determined. Rhizosphere oxidizing potential of each variety was determined by visualizing oxidizing power of rice roots embedded in a semisolid agar medium containing $\mathrm{Fe}$ sulfide. Results indicated that presence of soil microorganisms significantly $(p<0.05)$ reduced dry matter yield but increased Fe uptake of all three varieties. However, in the presence of microorganisms, $\mathrm{Fe}$ uptake remained more consistent irrespective of the Fe concentration in growth medium. Root oxidizing power had a positive relationship with Fe toxicity tolerance. The rhizosphere oxidizing potentials were in the order of BW 267-3 > BW $363>$ BW272-6b. Plant-microbial interactions on growth and uptake of $\mathrm{Fe}, \mathrm{K}$ and $\mathrm{P}$ were more prominent in BW 363 and BW 272-6b compared to BW 267-3. The results suggest that microorganisms mobilize $\mathrm{Fe}$ to rice plants. Further, remarkable differences exist among the rice varieties in root oxidizing power, and plant-microbial interactions depend on the Fe toxicity tolerance.

\footnotetext{
*Corresponding author: warshisd@pdn.ac.lk
} 


\section{INTRODUCTION}

Rice growers are in a continuing struggle to reach the potential yield to cater to the food demands of the continuously increasing population (Papademetriou et al., 2000). Iron toxicity is a common nutritional disorder that contribute to this yield gap in wetland rice cultivation, especially in the humid tropical regions (Audebert \& Fofana, 2009; Papademetriou et al., 2000; Sahrawat, 2000). Yield reduction due to Fe toxicity generally ranges from 15 to $75 \%$, but losses up to $100 \%$ can be observed, depending on the rice genotype, soil fertility status and severity of the stress (Audebert \& Fofana, 2009; Becker \& Asch, 2005; Sahrawat, 2004). Using resistant genotypes of the crop is the most promising approach so far available to increase productivity of Fe toxic soils (Bierschenk et al., 2019; Engel et al., 2012). Understanding adaptation strategies of plants is helpful to facilitate future genotype screening and breeding of Fe toxicity resistance in rice (Engel et al., 2012).

Iron toxicity has been reported in several countries in Asia, South America, West and Central Africa (Audebert \& Fofana, 2009; Bandara \& Gunatilaka, 1994; Papademetriou et al., 2000; Sahrawat, 2004). It has been observed in a wide range of soil types inherently rich in Fe such as acid sulphate soils, peat soils and acidic clay soils in valley bottoms that receive interflow water from nearby upper slopes, and generally under lowland rice production with permanent flooding during growth (Becker \& Asch, 2005; Sahrawat, 2004). Flooding of rice grown soils lead to depletion of oxygen that encourage the use of $\mathrm{Fe}^{3+}, \mathrm{NO}_{3}{ }^{-}$, and $\mathrm{Mn}^{4+}$ as electron acceptors by anaerobic microorganisms (Becker \& Asch, 2005). Microbial reduction of $\mathrm{Fe}$ oxides and hydroxides (having $\mathrm{Fe}^{3+}$ ) mobilize Fe increasing concentration of $\mathrm{Fe}^{2+}$ in soil solution, which is assimilated by plants. Excessive uptake of $\mathrm{Fe}^{2+}$ causes oxidative stress in plants via Fenton reaction (Krohling et al., 2016). High concentrations of $\mathrm{Fe}^{2+}$ in the soil solution cause imbalance of nutrient uptake, especially $\mathrm{P}, \mathrm{K}$, $\mathrm{Ca}, \mathrm{Mg}, \mathrm{Zn}$ and $\mathrm{Mn}$ (Audebert \& Fofana, 2009; Bierschenk et al., 2019; Engel et al., 2012; Fageria et al., 2008; Sahrawat, 2004). The critical concentration for occurrence of Fe toxicity is 300 ppm in soil solution (Dobermann \& Fairhurst, 2000). But the concentrations of Fe in soil solution that affect lowland rice production can vary from 10 to $2000 \mathrm{ppm}$ (Kirk, 2004). In addition to Fe concentration of soil solution, crop growth stage, physiological status of plant, genotypic characters, and plant-microbial interactions may contribute to the severity of Fe toxicity related stress experience by a crop.
Rice roots have three functions to counteract Fe toxicity (Sahrawat, 2010; Tadano \& Yoshida, 1978). They are; release of Oxygen to rhizosphere resulting oxidation of $\mathrm{Fe}^{2+}$ in the root zone soil, which keeps the concentration of mobile Fe species at low level in growth media; exclusion of $\mathrm{Fe}$ at the root surface that prevents the Fe from entering the root; and retention of $\mathrm{Fe}$ in the root tissue that decreases the translocation of $\mathrm{Fe}$ from root to shoot. Trolldenier (1988) reported that rhizosphere oxidation status is different among rice varieties and it clearly correlates with the $\mathrm{Fe}$ toxicity tolerance, since rhizosphere is a potential site of $\mathrm{Fe}^{2+}$ oxidation. However, the contribution of soil microorganisms in rhizosphere oxidizing power for Fe toxicity tolerance is not well studied.

In Sri Lanka, approximately $1 / 3$ of rice cultivated lands in low country wet zone (LCWZ) are considered to be potentially Fe toxic (Bandara \& Gunatilaka, 1994). Average rice yield of LCWZ is as low as $2.4 \mathrm{t} /$ ha while the potential yield is around $6 \mathrm{t} /$ ha mainly due to Fe toxicity (Abeysiriwardena, 2016). This study was conducted with three rice varieties with different Fe toxicity tolerance levels (susceptible, moderately tolerant, and tolerant to Fe toxicity) to investigate whether soil microorganisms affect Fe uptake by rice plant and whether there are any varietal differences in relation to rhizosphere oxidizing powers.

\section{METHODOLOGY}

The study was carried out at Regional Rice Research and Development Centre (RRDC), Bombuwala, located in $\mathrm{WL}_{4}$ agro-ecological region of Sri Lanka from July to November in 2012. Soil in the region is classified under great soil group Half Bog according to local classification.

\section{Preparation of nursery}

Three BW varieties of rice introduced by RRDC, Bombuwala were used in the experiment. With respect to their Fe toxicity tolerance characters, BW 267-3, BW 363 and BW 272-6b are considered as tolerant, moderately tolerant, and susceptible, respectively. Nursery beds were prepared using sterilized sand. For this sand was passed through 2 $\mathrm{mm}$ sieve, rinsed with water, air dried and autoclaved $\left(121{ }^{\circ} \mathrm{C}, 30\right.$ minutes). Electrical conductivity and $\mathrm{pH}$ of sand culture were measured in soil: water suspension (1:5) prior to set up the nursery. Rice seeds were surface sterilized with $1 \%$ sodium hypochlorite $(\mathrm{NaOCl})$ for 30 minutes., rinsed with sterilized distilled water five times and then soaked in sterilized 
water overnight (Bi et al., 2007). Then seeds were direct seeded into sand beds prepared on plastic trays separately for each variety. Sterilized distilled water was used for watering. One week after germination, quarter strength Albert's Solution ${ }^{\circledR}$ was added to sand culture as a nutrient solution. Marshel $20 \% \AA$ was applied to control thrips according to the manufacturer's directions after two weeks. At 21 days after germination (DAG) healthy and uniformly developed seedlings were obtained to transplant in pots.

\section{Establishment of pot experiment}

The experiment was conducted in a three-factor factorial design. The main factor treatments were growth media with and without soil microorganisms. The subplot factor was three $\mathrm{Fe}$ levels $(2 \mathrm{mg} / \mathrm{L}, 75 \mathrm{mg} / \mathrm{L}$ and $300 \mathrm{mg} / \mathrm{L})$. Three rice varieties were used in each subplot treatment. Four replicates were used in the study. Pot experiment was established using double pot method, where inner pot served as the planting compartment and outer cup served as the nutrient solution reservoir. A disposable plastic cup (200 $\mathrm{mL}$ capacity and $8 \mathrm{~cm}$ in height) perforated on sides and bottoms was inserted into a second plastic cup ( $350 \mathrm{~mL}$ capacity and $12 \mathrm{~cm}$ in height), and washed and sterilized sand (heated at $120^{\circ} \mathrm{C}$ for one hour) was filled into the inner cups to plant seedlings.

Two treatments in relation to presence of microorganisms were imposed as growth media with soil microorganisms (MO+) and without soil microorganisms (MO-) before transplanting rice. Paddy soils harbor highly diverse microbial populations (Liesack et al., 2000). Therefore, fieldfresh soil from a paddy field can be used as an inoculum to introduce natural microbial flora to the growth medium in pot experiment. A bulk soil sample was collected from a paddy field at RRDC, Bombuwala and analyzed for total $\mathrm{N}$, available $\mathrm{P}$ and exchangeable K content (Dharmakeerthi et al., 2007). A slurry was prepared by suspending fieldfresh soil in sterilized distilled water (1:5) and filtering through a folded sterilized cheese-cloth to remove debris and large particles. In $\mathrm{MO}+$ treatment, microorganisms were introduced by mixing the field-fresh soil slurry with sterilized sand in the pot. In here, the slurry was filled into nutrient solution reservoir compartment of pots receiving non-sterilized treatment and incubated for one day. Then planting compartments were completely drained. This introduction of microorganisms was done only once. Soil slurry was autoclaved at $121{ }^{\circ} \mathrm{C}$ for 30 minutes to kill the microorganisms before repeating the same steps for MO- treatment.
Two seedlings were transplanted per pot. Nutrient solution developed by Yoshida et al. (1976) was used in the study (N, K, Ca and $\mathrm{Mg}$ each at $40 \mathrm{mg} / \mathrm{L}$, $\mathrm{P}$ at $10 \mathrm{mg} / \mathrm{L}, \mathrm{Zn}$ and $\mathrm{Cu}$ each at $0.01 \mathrm{mg} / \mathrm{L}$, Mo at $0.05 \mathrm{mg} / \mathrm{L}, \mathrm{B}$ at $0.2 \mathrm{mg} / \mathrm{L}, \mathrm{Mn}$ at $0.5 \mathrm{mg} / \mathrm{L}$ ) with a modification to supply respective Fe treatment (2, 75 and $300 \mathrm{mg} / \mathrm{L}$ ) using $\mathrm{FeSO}_{4} .7 \mathrm{H}_{2} \mathrm{O}$ as the source. The nutrient solution reservoir compartments of all pots were filled with the nutrient solution with respective Fe treatment and renewed once a week throughout the experiment.

At 42 DAG when plants were at tillering stage, plants were uprooted, cleaned, and fresh weights were recorded. Then plants were dried at $40{ }^{\circ} \mathrm{C}$ until a constant weight is reached to record dry weights. Roots and shoots were separated and only shoots were analyzed for nutrients. The plant leaves obtained from same varieties at same growth stage grown in the field, which showed Fe toxicity symptoms were also analyzed for tissue nutrient levels for comparison purpose. Shoots were finely grinded and digested with $\mathrm{HNO}_{3}: \mathrm{HClO}_{4}$ (60\%), 9:4 mixture (Westerman, 1990). Total Fe contents of the extract were measured using atomic absorption spectrophotometer (Shimadzu AA-6200) and total K contents were measured using a flame emission spectrophotometer (Jenway PSE7). Total $P$ was measured colorimetrically following ammonium vanada molybdate method (Westerman, 1990) and analyzing color using the spectrophotometer (Shimadzu UV-1601). Recovery efficiencies of Fe, P and $\mathrm{K}$ in shoot tissues were calculated using following formula;

$$
\text { Recovery efficiency }=\frac{c \times w}{A} \times 100
$$

where, $\boldsymbol{c}$ is the concentration of element per $1 \mathrm{~g}$ of shoot; $\boldsymbol{w}$ is the shoot weight per plant in grams and $\boldsymbol{A}$ is the weight of element added per plant to the growth medium in grams.

\section{Potential Rhizosphere Oxidizing Power Experiment}

Oxidizing power of rice roots were visualized by embedding pre-cultivated plants in a semisolid agar medium containing $\mathrm{Fe}$ sulfide ( $\mathrm{FeS}$ ) that blacken the medium following the method described by Trolldenier (1988). As a result of solubilization of $\mathrm{FeS}$ by oxygen exude from rice roots, a transparent zone is created around roots and the width of this clearing zone is an indication of the oxidizing power of roots. Method in brief, at 21 DAG uniformly developed healthy seedlings of rice from the nursery were transplanted as one seedling per pot and grown hydroponically suspending roots in the nutrient solution proposed 
by Yoshida et al. (1976). Nutrient solution was renewed once a week. A semisolid agar medium containing FeS was prepared by modifying nutrient solution proposed by Yoshida et al. (1976). In here, $\mathrm{CaCO}_{3}(10 \mathrm{mM}), \mathrm{FeSO}_{4} .7 \mathrm{H}_{2} \mathrm{O}(5 \mathrm{mM}), \mathrm{Na}_{2} \mathrm{~S}(4 \mathrm{mM})$ and agar $(0.4 \%)$ were added to the medium and $\mathrm{pH}$ was adjusted to 5.3. At 42 DAG, plants were transferred to rhizotrons made from glass boxes filled with semisolid agar medium containing $\mathrm{FeS}$ in triplicates (Figure 1a and $1 \mathrm{~b}$ ). While setting up rhizotrons, care was taken to spread the root system along glass wall. After 24 hours, images of roots spreading along glass wall were captured (Figure 1c). The root diameter and the width of clearing zone were measured using cell profiler image analyzing software (http://www. cellprofiler.org).

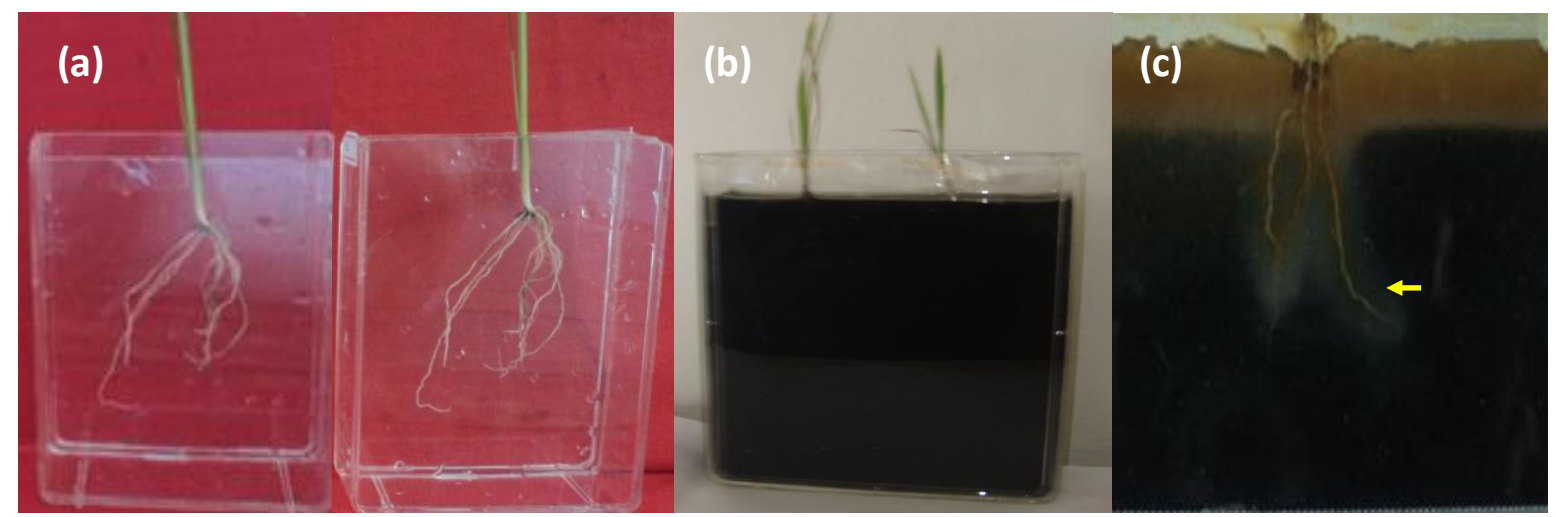

Figure 1. Preparation of rhizotrons for studying oxidizing potential of rice roots. (a) Placement of 42 days old rice plants in glass boxes; (b) Glass boxes filled with semisolid agar medium containing FeS (c) Clearing zone created (indicated by arrow) around roots of BW 267-3 variety after $24 \mathrm{~h}$.

\section{Statistical Analysis}

Data from the pot experiment were analyzed using three-factor factorial design by conducting analysis of variance (ANOVA) with generalized linear model (GLM) procedure. The presence of microorganisms, Fe treatment and rice variety were used as the three groups in factorial analysis. When the main effect or the interaction effect was significant, the mean comparison was performed with least significant difference (LSD) mean separation technique. The correlations between different parameters were assessed using Pearson's correlation test. The effect of variety on potential oxidation power of roots was determined by ANOVA and means were compared with LSD method. Statistical significance in all analyses were determined at $p=0.05$. Statistical analyses were performed using SPSS 17.0. software.

\section{RESULTS AND DISCUSSION}

The soil used to prepare the slurry contained $0.098 \%$ of total $\mathrm{N}, 7.52 \mathrm{mg} / \mathrm{kg}$ of available $\mathrm{P}, 3.7$ $\mathrm{mg} / \mathrm{kg}$ of $\mathrm{K}$ and $180 \mathrm{mg} / \mathrm{kg}$ of Fe. After treating the sand medium with the slurry, Fe content in sand medium was $16.65 \mathrm{mg} / \mathrm{kg}$. Therefore, even though the least quantity of Fe added through Fe treatment was $2 \mathrm{mg} / \mathrm{L}$, the growth medium contained a higher level of Fe than intended, which may mask the treatment effects. However, $16 \mathrm{mg} / \mathrm{kg}$ is not toxic. Dry matter production of 42 days old plants was significantly $(p<0.05)$ affected by the presence of soil microorganisms (Table 1 ) but not by the Fe treatment ( $p>0.05)$. In BW 272-6b and BW 363 varieties, dry matter yield was significantly high in the absence of microorganisms; whereas, the dry matter production of the $\mathrm{Fe}$ toxicity tolerant variety BW 267-3 was not significantly affected by the presence of microorganisms. In this study, the symptoms of Fe toxicity occurred mostly on susceptible variety. Kirk (2004) reported that Fe toxicity symptoms can occur at different growth stages and affect at the seedling stage, vegetative growth, and at the early and late reproductive stages. Toxicity during the vegetative stages is associated with reduced plant height and poor dry matter gain (Abu et al., 1989), with the shoot being more affected than the root biomass (Fageria, 1988). 
Table 1. Total dry matter production and dry matter partitioning between shoots and roots of three rice varieties with different Fe toxicity tolerance characters (tolerant - BW 267-3, moderately tolerant - BW 363 and susceptible - BW 272-6b) subjected to three Fe levels $(2,75$ and $300 \mathrm{mg} / \mathrm{L})$ in the growth medium in the presence (MO+) and absence (MO-) of soil microorganisms.

\begin{tabular}{|c|c|c|c|c|}
\hline \multirow{2}{*}{$\begin{array}{l}\text { Rice variety and } \mathrm{Fe} \\
\text { treatment }\end{array}$} & \multicolumn{2}{|c|}{ Total dry matter yield (g/plant) } & \multicolumn{2}{|c|}{ Dry weight ratio of Shoot:Root } \\
\hline & $\mathrm{MO}+$ & MO- & MO+ & MO- \\
\hline \multicolumn{5}{|l|}{ BW 267-3 } \\
\hline $\mathrm{Fe}-2$ & $0.06 \pm 0.03^{\mathrm{A}}$ & $0.10 \pm 0.07^{\mathrm{A}}$ & $0.96 \pm 0.70^{\mathrm{A}}$ & $1.55 \pm 0.61^{\text {в }}$ \\
\hline Fe-75 & $0.06 \pm 0.01^{\mathrm{A}}$ & $0.07 \pm 0.03^{\mathrm{A}}$ & $0.67 \pm 0.27^{\mathrm{A}}$ & $0.82 \pm 0.48^{\mathrm{A}}$ \\
\hline $\mathrm{Fe}-300$ & $0.06 \pm 0.01^{\mathrm{A}}$ & $0.08 \pm 0.04 \mathrm{~A}$ & $0.61 \pm 0.08^{\mathrm{A}}$ & $0.53 \pm 0.23 \mathrm{~A}$ \\
\hline \multicolumn{5}{|l|}{ BW 363} \\
\hline Fe-2 & $0.05 \pm 0.01^{\mathrm{A}}$ & $0.15 \pm 0.10^{\text {в }}$ & $0.85 \pm 0.53^{\mathrm{A}}$ & $1.10 \pm 0.08 \mathrm{~A}$ \\
\hline $\mathrm{Fe}-75$ & $0.04 \pm 0.01^{\mathrm{A}}$ & $0.18 \pm 0.10^{\mathrm{B}}$ & $1.04 \pm 0.67^{\mathrm{A}}$ & $0.95 \pm 0.33 \mathrm{~A}$ \\
\hline Fe-300 & $0.05 \pm 0.01^{\mathrm{A}}$ & $0.14 \pm 0.09^{\text {в }}$ & $0.79 \pm 0.25^{\mathrm{A}}$ & $0.60 \pm 0.41^{\mathrm{A}}$ \\
\hline \multicolumn{5}{|l|}{ BW 272-6b } \\
\hline $\mathrm{Fe}-2$ & $0.03 \pm 0.01^{\mathrm{A}}$ & $0.15 \pm 0.10^{\text {в }}$ & $0.75 \pm 0.29^{\mathrm{A}}$ & $0.71 \pm 0.24^{\mathrm{A}}$ \\
\hline Fe-75 & $0.03 \pm 0.01 \mathrm{~A}$ & $0.11 \pm 0.08$ в & $0.67 \pm 0.24 \mathrm{~A}$ & $0.89 \pm 0.55^{\mathrm{A}}$ \\
\hline Fe-300 & $0.03 \pm 0.01^{\mathrm{A}}$ & $0.10 \pm 0.02^{\text {в }}$ & $0.63 \pm 0.25^{\mathrm{A}}$ & $0.45 \pm 0.51^{\mathrm{A}}$ \\
\hline
\end{tabular}

Source

Soil treatment (TS) *** Ns

Variety (TV)

Ns

Ns

Fe treatment (TFe)

Ns

Interaction effects

$* 1$

Ns

- $\quad$ The means followed by same letter for presence or absence of microorganisms soil treatments (MO+ and MO- respectively) for a given Fe treatment in a given rice variety are not significantly different (p at 0.05).

The effects followed by ${ }^{*}, * *$, and ${ }^{* * *}$ are significant at $p$ value $<0.05,<0.01$ and $<0.001$, respectively. $n s=$ Not significant $(p>0.05)$.

- $\quad{ }^{1}$ Only the interaction effect TS*TV was significant

Supplying Fe at $300 \mathrm{mg} / \mathrm{L}$ significantly $(p<0.05)$ reduced shoot: root ratio compared to other two $\mathrm{Fe}$ treatments, especially when rice was cultivated with no soil microorganisms in the root zone (Table 1). Nutrient uptake by plant could decrease due to reduction of effective root zone for nutrient assimilation as a result of formation of Fe plaque when rice is grown in $\mathrm{Fe}$ toxic conditions (Liesack et al., 2000; Tadano, 1975). Therefore, plants would tend to invest more on increasing root growth than under non-iron toxic situation. In addition, oxygen release from roots help to oxidize $\mathrm{Fe}^{2+}$ ions at locations with dense root systems such as near the surface of rice paddy soils and this would help the plant to cope up with Fe toxicity (Liesack et al., 2000; Ratering \& Schnell, 2016).
Soil microorganisms may help the plants to cope with $\mathrm{Fe}$ toxicity by supporting with nutrient scavenging and uptake and also by other mechanism to avoid excess Fe uptake to plants such as by producing siderophores. Microbial siderophores are low molecular weight ligands which can chelate $\mathrm{Fe}$ from soil (Ahmed \& Holmström, 2014). Although not significant higher shoot: root ratio of plants was observed in the presence of microorganisms compared to that under absence of microorganisms when plants were grown in $\mathrm{Fe}$ toxic conditions ( $\mathrm{Fe}$ at $300 \mathrm{mg} / \mathrm{L}$ concentration in growth medium). Plant stress cause by $\mathrm{Fe}$ toxicity may be alleviated to some extent by the microorganisms relieving burden on investing more for root systems. However, concentrations of $\mathrm{Fe}, \mathrm{K}$ and $\mathrm{P}$ in shoot tissues were 
significantly $(p<0.05)$ enhanced in the presence of soil microorganisms (Table 2). It was noted that the presence of microorganisms in the growth medium resulted in significantly $(p<0.01)$ higher Fe concentration in plant tissues (Table 2) and significantly lower dry biomass (Table 1) for BW 272-6b (susceptible variety) compared to BW 267 3 (tolerant variety). However, in the absence of microorganisms, such trends were not observed. Further, in all three varieties, the Fe concentration in plant tissues increased with the $\mathrm{Fe}$ concentration in the growth medium only when the microorganisms were absent (Table 2). When considering the nutrient uptake in shoots, the effect of microorganisms remained significant $(p<0.05)$ and positive only on the uptake of $\mathrm{Fe}$ (Figure 2A). Therefore, presence of microorganisms should have increased only the Fe uptake by plants. These observations suggest that microorganisms should have an important role in Fe nutrition of rice plants.

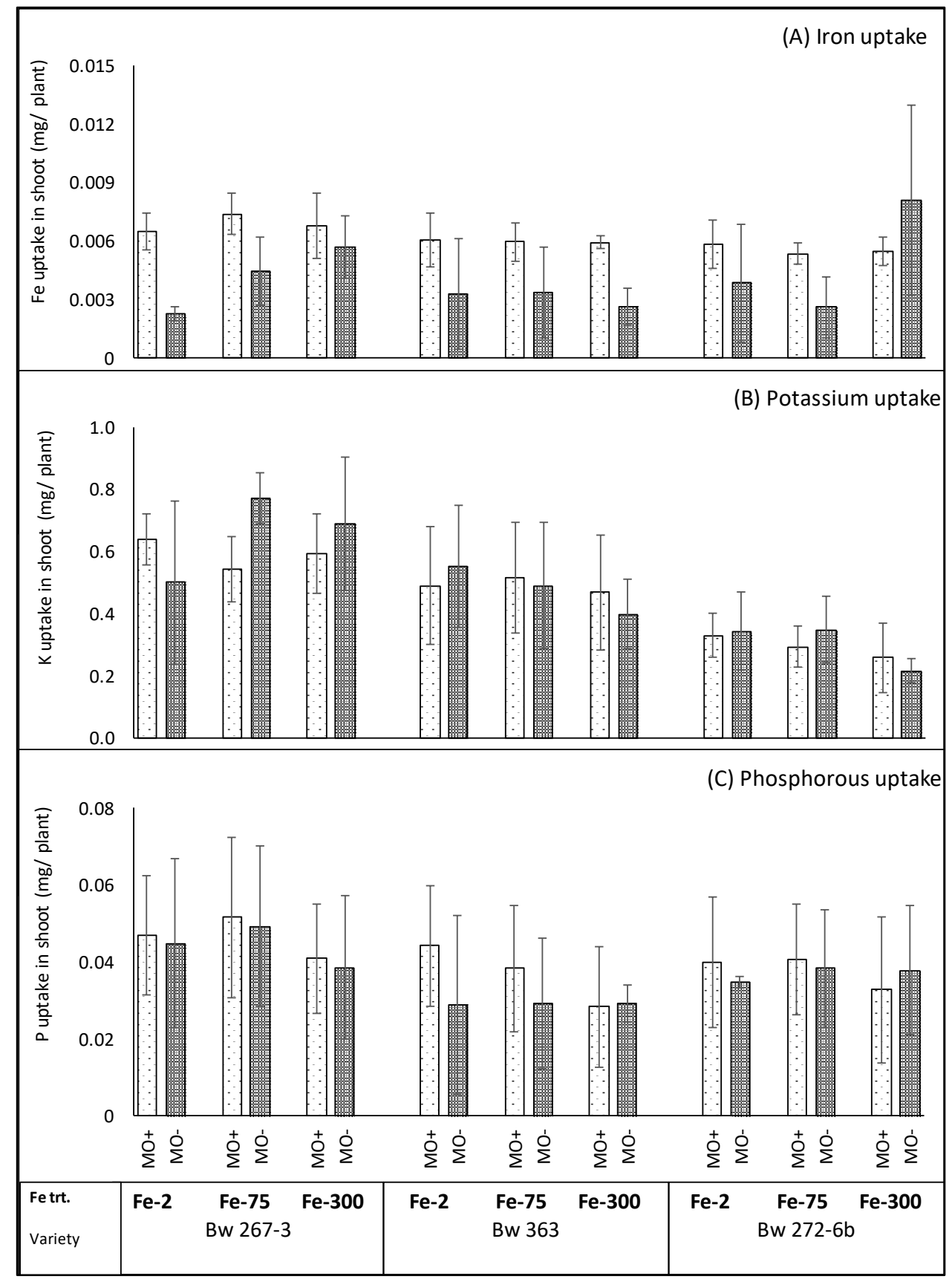

Figure 2. Uptake of Fe, $\mathrm{K}$ and $\mathrm{P}$ in shoots of 42 days old plants of three rice varieties with different Fe toxicity tolerance characters (tolerant - BW 267-3, moderately tolerant - BW 363 and susceptible - BW 272-6b) subjected to three Fe levels (2, 75 and $300 \mathrm{mg} / \mathrm{L}$ ) in the growth medium in the presence (MO+) and absence (MO-) of soil microorganisms 
Microorganisms play a crucial role under flooded conditions in reducing $\mathrm{Fe}^{3+}$ into soluble $\mathrm{Fe}^{2+}$ (Ponnamperuma, 1972). Similar to a number of redox reactions happening in the rice rhizosphere environment, $\mathrm{Fe}$ oxidation and reduction is also tightly coupled and predominantly microbiologically mediated (Liesack et al., 2000). Therefore, both $\mathrm{Fe}$ reducing and $\mathrm{Fe}$ oxidizing bacteria should have been introduced to sand culture when inoculating with soil slurry originated from a rice paddy soil. Wang and Liu (1992) reported that the abundance of Fe-reducing microorganisms may be higher in the rhizosphere than in the bulk soil. Microorganisms introduced to the growth media may have involved in increasing $\mathrm{Fe}^{2+}$ concentration that can be taken up by plants.

The varietal differences were not significant $(p>0.05)$ for the Fe and P uptake in shoot. But K uptake was significantly $(p<0.05)$ different among three varieties. Although not significant $(p>0.05)$ the Fe toxicity tolerant variety had the highest $\mathrm{P}$ uptake (Figure 2B). The Fe toxicity tolerant and moderately tolerant varieties showed a significantly $(p<0.05)$ high uptake of $\mathrm{K}$ than the susceptible variety (Figure $2 \mathrm{C}$ ). These two varieties also had high root dry matter contents than the susceptible variety (Table 1). According to Sabir et al. (2003), there is a positive correlation between $\mathrm{K}$ uptake and root dry matter content of rice plant.

Concentration of elements in plant tissues could be partly due to the dilution effect from biomass accumulation (Sahrawat, 2000). A significantly $(p<0.001)$ strong negative correlation was observed between dry biomass accumulation and concentrations of $\mathrm{P}$ and $\mathrm{K}$ in shoot tissues $(\mathrm{r}=-0.62$ and $\mathrm{r}=-0.75$ respectively). The uptake of $\mathrm{Fe}$ in shoots of the Fe tolerant rice variety (Bw 267-3) increased with increasing $\mathrm{Fe}$ concentration in the growth medium from 2 to $300 \mathrm{mg} / \mathrm{L}$ in the absence of soil microorganisms (Figure 2A). However, in the presence of microorganisms, $\mathrm{Fe}$ uptake remained high and more consistent irrespective of the Fe concentration in the growth medium (Figure 2A). Shoot tissue concentration of Fe increased with the increase in susceptibility of the plants to Fe toxicity. Variety susceptible to Fe toxicity had the significantly highest Fe concentration in shoots (Table 2). The critical concentration of Fe in plant tissues is considered as $300 \mathrm{mg}$ of $\mathrm{Fe} / \mathrm{kg}$ dry weight of plant (Sahrawat, 2000), and the concentration of Fe in shoot tissues of plants grown in the presence of microorganisms were around this value in $\mathrm{Fe}$ toxicity tolerant and moderately tolerant rice varieties while the variety susceptible to Fe toxicity (BW 272-6b) having concentrations exceeding the critical limit by over $100 \mathrm{mg} \mathrm{Fe} / \mathrm{kg}$ dry weight of plant (Table 2). In a field study conducted in Fe toxic soils in Korhogo, Ivory Coast, nearly ten times higher Fe concentrations than those observed in the present study have been reported in rice shoots sampled at 30 days after transplanting (Sahrawat, 2000). The concentration of $\mathrm{Fe}$ in rice plants grown in non-iron toxic soils are reported in the range of 100 to $320 \mathrm{mg} / \mathrm{kg}$ of plant dry matter (Sahrawat, 2000). In our study, the plants were exposed to Fe treatment only for three weeks. The effect of Fe treatment on plant growth was visible even after that relatively short exposure time.

The concentration of $\mathrm{P}$ in shoot tissues followed the same trend as $\mathrm{Fe}$; i.e. P concentration increasing with the presence of microorganisms in root environment and also with increasing susceptibility of variety to Fe-toxicity (Table 2). The observed $\mathrm{P}$ and $\mathrm{K}$ concentrations in rice shoots are comparable to those reported in literature and were at sufficient level for plant growth (Sahrawat, 2000). Shoot tissue concentration of $\mathrm{Fe}$ had a strong positive correlation with shoot $\mathrm{P}$ concentration $(r=0.79, p<0.001)$ and shoot $K$ concentration $(r=0.59, \mathrm{p}<0.001)$ and a strong negative correlation with dry biomass yield $(\mathrm{r}=$ $0.60, p<0.001$ ). Same trends although significant but weak were observed as for the correlations between $\mathrm{Fe}$ uptake in shoots and concentration and uptake of $\mathrm{P}$ in $\operatorname{shoot}(\mathrm{r}=0.41, \mathrm{p}<0.001$ and $\mathrm{r}=$ $0.29, p<0.05$, respectively), concentration of $K$ in shoot $(r=0.24, p<0.05)$ and dry biomass yield $(r=$ $-0.27, \mathrm{p}<0.05$ ). However, $\mathrm{P}$ and $\mathrm{K}$ uptake in shoots were not significantly affected by Fe treatment or the presence of microorganisms in the soil (Figure $2 \mathrm{~B}$ and $2 \mathrm{C}$ ). With the increasing level of Fe content in growth medium, the formation of $\mathrm{Fe}$ plaque is also increased and this was observed in the present study as well. Plaque is formed as a result of converting $\mathrm{Fe}^{2+}$ to $\mathrm{Fe}^{3+}$ and depositing them on root surface under aerobic conditions. It can act as a barrier to uptake nutrients as well as a reservoir for nutrients. Yoshida (1981) reported that the high concentration of $\mathrm{Fe}$ in soil solution decreases the nutrient uptake, especially P and K. Quadratic decrease in $\mathrm{P}$ and $\mathrm{K}$ uptake by rice plants when $\mathrm{Fe}$ concentration in solution increased from 0 to 160 $\mathrm{mg} / \mathrm{L}$ has been reported previously (Fageria et al., 2008). However, there was no significant effect of Fe concentration in sand culture on $\mathrm{P}$ and $\mathrm{K}$ uptake in the present study. The efficiency of recovering $\mathrm{Fe}, \mathrm{P}$ and $\mathrm{K}$ in shoots (uptake in shoots per unit of element added expressed as a percentage) was in the range of 0.001 to $0.64 \%, 0.09$ to $1.16 \%$ and 0.43 to $3.94 \%$ respectively. This indicates that these elements were adequately provided in sand culture. 
Table 2. Concentration of Fe, $\mathrm{K}$ and $\mathrm{P}$ in shoot tissues of 42 days old plants of three rice varieties with different Fe toxicity tolerance characters (tolerant - BW 267-3, moderately tolerant - BW 363 and susceptible - BW 272-6b) subjected to three Fe levels (2, 75 and $300 \mathrm{mg} / \mathrm{L})$ in the growth medium in the presence (MO+) and absence (MO-) of soil microorganisms.

\begin{tabular}{|c|c|c|c|c|c|c|}
\hline \multirow{2}{*}{$\begin{array}{c}\text { Rice variety and Fe } \\
\text { treatment }\end{array}$} & \multicolumn{2}{|c|}{ Fe concentration $(\mathrm{mg} / \mathrm{kg})$} & \multicolumn{2}{|c|}{ K concentration (mg/kg) } & \multicolumn{2}{|c|}{ P concentration (mg/kg) } \\
\hline & $\mathrm{MO}+$ & MO- & $\mathrm{MO}+$ & MO- & $\mathrm{MO}+$ & MO- \\
\hline \multicolumn{7}{|l|}{ BW 267-3 } \\
\hline $\mathrm{Fe}-2$ & $295 \pm 52 \mathrm{~A}$ & $62 \pm 36^{\mathrm{B}}$ & $29129 \pm 5729 \mathrm{~A}$ & $16571 \pm 13055^{\mathrm{A}}$ & $2231 \pm 970^{A}$ & $1487 \pm 1303^{A}$ \\
\hline $\mathrm{Fe}-75$ & $337 \pm 73^{A}$ & $169 \pm 73^{A}$ & $24425 \pm 3788^{A}$ & $28879 \pm 6572 A$ & $2353 \pm 1081^{A}$ & $1790 \pm 622^{A}$ \\
\hline Fe-300 & $317 \pm 113^{A}$ & $331 \pm 285 \mathrm{~A}$ & $26827 \pm 5911 \mathrm{~A}$ & $34935 \pm 19674^{A}$ & $1929 \pm 872$ А & $2315 \pm 2138^{A}$ \\
\hline \multicolumn{7}{|l|}{ BW 363} \\
\hline $\mathrm{Fe}-2$ & $323 \pm 188^{A}$ & $38 \pm 13$ в & $25226 \pm 12367 \mathrm{~A}$ & $13140 \pm 14870 \mathrm{~A}$ & $2531 \pm 2049 \mathrm{~A}$ & $360 \pm 119$ в \\
\hline $\mathrm{Fe}-75$ & $359 \pm 95^{A}$ & $45 \pm 21^{\text {в }}$ & $31532 \pm 12830 \mathrm{~A}$ & $11280 \pm 13342$ в & $2250 \pm 751^{A}$ & $377 \pm 121^{A}$ \\
\hline Fe-300 & $352 \pm 194 \mathrm{~A}$ & $118 \pm 122$ в & $24825 \pm 7988$ A & $20956 \pm 19536 \mathrm{~A}$ & $1491 \pm 740^{\mathrm{A}}$ & $1474 \pm 1353^{\mathrm{A}}$ \\
\hline \multicolumn{7}{|l|}{ BW 272-6b } \\
\hline $\mathrm{Fe}-2$ & $500 \pm 152 \mathrm{~A}$ & $63 \pm 9 B$ & $27628 \pm 4275^{A}$ & $15083 \pm 18687 \mathrm{~A}$ & $3345 \pm 1549$ A & $1307 \pm 1440^{\mathrm{B}}$ \\
\hline Fe-75 & $465 \pm 135 \mathrm{~A}$ & $67 \pm 31$ в & $24625 \pm 4440 \mathrm{~A}$ & $10721 \pm 7114$ A & $3362 \pm 1054 \mathrm{~A}$ & $1758 \pm 2234 \mathrm{~A}$ \\
\hline Fe-300 & $548 \pm 75^{\text {A }}$ & $424 \pm 282 \mathrm{~A}$ & $25826 \pm 11204^{A}$ & $13564 \pm 7005$ A & $3285 \pm 1901^{A}$ & $2620 \pm 2350^{\mathrm{A}}$ \\
\hline \multicolumn{7}{|l|}{ Source } \\
\hline Soil treatment (TS) & \multicolumn{2}{|c|}{$* * *$} & \multicolumn{2}{|c|}{$* *$} & \multicolumn{2}{|c|}{$* *$} \\
\hline Variety (TV) & \multicolumn{2}{|c|}{$* *$} & \multicolumn{2}{|c|}{ Ns } & \multicolumn{2}{|c|}{$*$} \\
\hline Fe treatment (TFe) & \multicolumn{2}{|c|}{$* *$} & \multicolumn{2}{|c|}{ Ns } & \multicolumn{2}{|c|}{ Ns } \\
\hline Interaction effects & \multicolumn{2}{|c|}{$* 1$} & \multicolumn{2}{|c|}{ Ns } & \multicolumn{2}{|c|}{ Ns } \\
\hline
\end{tabular}

- $\quad$ The means followed by same letter for non-sterilized and sterilized soil treatments for a given Fe treatment in a given rice variety are not significantly different ( $p$ at 0.05).

The effects followed by ${ }^{*}, * *$, and ${ }^{* * *}$ are significant at $p$ value $<0.05,<0.01$ and $<0.001$, respectively. ns=Not significant ( $p>0.05$ )

- $\quad 1$ Only the interaction effect TS*TV and TS*TFe were significant 
Exuding air into the rhizosphere environment by rice roots facilitate oxidation and subsequent precipitation $\mathrm{Fe}^{3+}$ discouraging the assimilation of Fe by rice plants (Fageria et al., 2008; Tadano, 1975). Trolldenier (1977) reported that deficiencies of $\mathrm{K}$ and $\mathrm{P}$ reduce oxidizing capacity of rice roots aggravating the effects of Fe toxicity on plant performance. Analysis of potential rhizosphere oxidizing power indicated varietal differences with respect to this parameter with the tolerant variety exhibiting the highest oxidizing power (Figure 3). Therefore, $\mathrm{Fe}^{2+}$ made available by microbial reduction process may be oxidized back to $\mathrm{Fe}^{3+}$ in rhizosphere environment of the $\mathrm{Fe}$ toxicity tolerant variety more than in moderately susceptible and susceptible varieties.

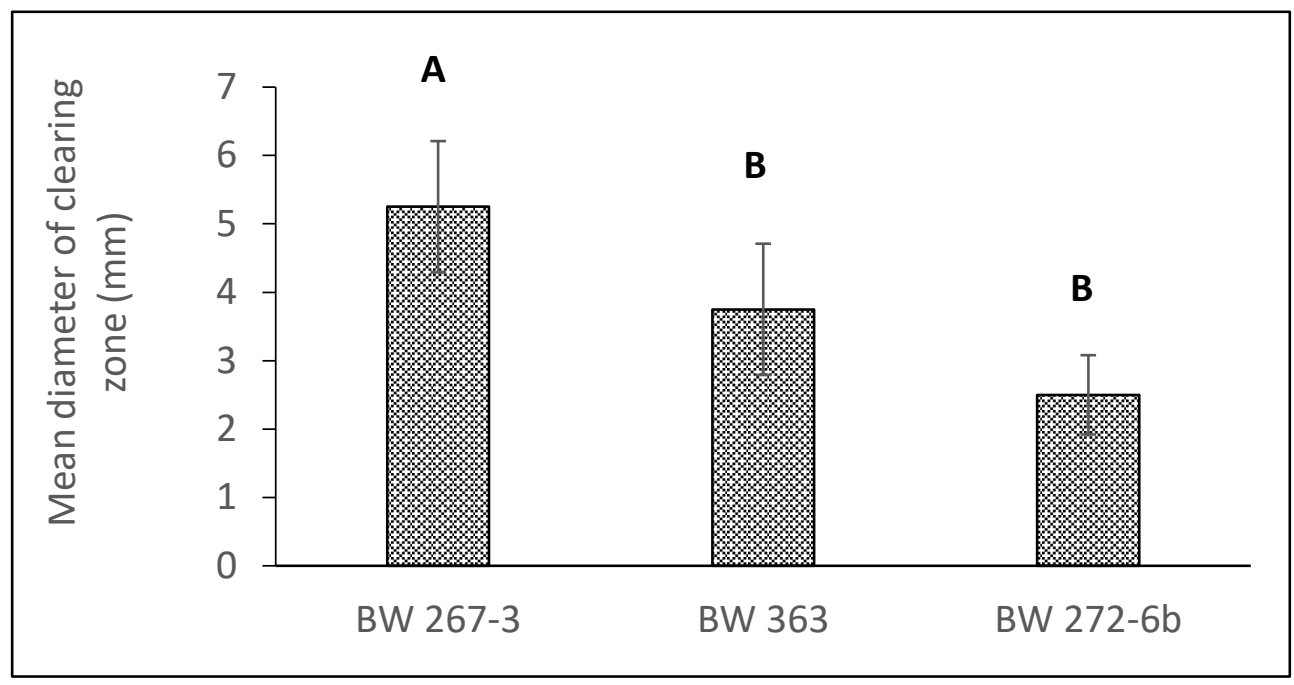

Figure 3. Diameter of the clearing zone created by three rice varieties with different Fe toxicity tolerance characters (tolerant - BW 267-3, moderately tolerant - BW 363 and susceptible - BW 2726b) in FeS medium in analysis of potential oxidizing ability of rice roots using a rhizotron experimental set-up

\section{CONCLUSIONS}

Plant-microbial interaction in dry matter yield and uptake of $\mathrm{Fe}, \mathrm{K}$ and $\mathrm{P}$ were more prominent in $\mathrm{BW}$ 363 and BW 272-6b rice varieties which are moderately tolerant and susceptible, respectively, to Fe toxicity in comparison to BW 267-3, which is an Fe toxicity tolerant variety. In overall, the presence of microorganisms in the root environment increased Fe uptake by rice plant but maintained $\mathrm{Fe}$ concentration in plant tissues at a more consistent level close to critical concentration $(300 \mathrm{mg} / \mathrm{kg})$ for plant growth irrespective of the Fe concentration in sand culture medium. In the absence of microorganisms, tissue concentration of $\mathrm{Fe}$ increased with increasing $\mathrm{Fe}$ content in the growth medium. The root oxidizing power seems to have a direct relationship with Fe toxicity tolerance of a rice variety. BW 267-3 had the highest root oxidizing potential. More rice varieties with varying Fe toxicity tolerance need to be tested to confirm the relationship between Fe toxicity tolerance and root oxidizing power. Such information will be useful in efficient screening of rice varieties in breeding programs targeting increasing productivity of Fe toxic soils.

\section{REFERENCES}

Abeysiriwardena, D. S. D. Z. (2016). Yield potential, potential yield and realized yield at farmer level of cereals with special reference to rice (Oryza sativa L.). Sri Lanka Journal of Food and Agriculture, 2(1).1-17.

Abu, M. B., Tucker, E. S., Harding, S. S., \& Sesay, J. S. (1989). Cultural practices to reduce iron toxicity in rice. International Rice Research Newsletter. 14(1), 19.

Ahmed, E., \& Holmström, S. J. M. (2014). Siderophores in environmental research: Roles and applications. Microbial Biotechnology. 7(3), 196-208. https://doi.org /10.1111/1751-7915.12117

Audebert, A. , \& Fofana, M. (2009). Rice yield gap due to iron toxicity in West Africa. Journal of Agronomy and Crop Science. 195(1), 66-76. https://doi.org/10.1111/j.1439037X.2008.00339.X

Bandara, W. M. J., \& Gunatilaka, G. A. (1994). Effects of Applied Potassium and Phosphorus on Bronzing in Rice Grown in Iron Toxic Soils. Journal of Natlonal Science Foundation of Sri 
Lanka. 22(3), 219-230. https://doi.org/ 10.4038/jnsfsr.v22i3.8123

Becker, M., \& Asch, F. (2005). Iron toxicity in rice Conditions and management concepts. Journal of Plant Nutrition and Soil Science. 168(4), 558-573. https://doi.org/ 10.1002/jpln.200520504

Bi, H. H., Zeng, R. S., Su, L. M., An, M., \& Luo, S. M. (2007). Rice allelopathy induced by methyl jasmonate and methyl salicylate. Journal of Chemical Ecology. 33(5), 1089-1103. https: //doi.org/10.1007/s10886-007-9286-1

Bierschenk, B., Tagele, M. T., Ali, B., Ashrafuzzaman, M., Wu, L. B., Becker, M., \& Frei, M. (2019). Evaluation of rice wild relatives as a source of traits for adaptation to iron toxicity and enhanced grain quality. PLoS One. 1-18. https://doi.org/10.1101/771352

Dharmakeerthi, R., Indraratne, S. P., \& Kumaragamage, D. (Eds.). (2007). Manual of soil sampling and analysis. Special publication No. 10, Soil Science society of Sri Lanka.

Dobermann, A., \& Fairhurst, T. (2000). Rice Nutrient Disorders \& Nutrient Management. In Handbook series Potash \& Phosphate Institute (PPI); Potash \& Phosphate Institute of Canada (PPIC). Canada (Vol. 11).

Engel, K., Asch, F., \& Becker, M. (2012). Classification of rice genotypes based on their mechanisms of adaptation to iron toxicity. Journal of Plant Nutrition and Soil Science. 175(6), 871-881. https://doi.org/ 10.1002/ jpln.201100421

Fageria, N. K. (1988). Influence of iron on nutrient uptake by rice. International Rice Research Newsletter. 13, 20-21.

Fageria, N. K., Santos, A. B., Barbosa Filho, M. P., \& Guimarães, C. M. (2008). Iron toxicity in lowland rice. Journal of Plant Nutrition. 31(9), 1676-1697. https://doi.org/10.1080 /0190 4160802244902

Kirk, G. J. D. (2004). The Biogeochemistry of Submerged Soils. John Wiley \& Sons. West Sussex, England. https://doi.org/ 10.1002/047086303x

Krohling, C. A., Eutrópio, F. J., Bertolazi, A. A., Dobbss, L. B., Campostrini, E., Dias, T., \& Ramos, A. C. (2016). Ecophysiology of iron homeostasis in plants. Soil Science and Plant Nutrition. 62(1), 39-47. https://doi.org/10. 1080/00380768.2015.1123116

Liesack, W., Schnell, S., \& Revsbech, N. P. (2000). Microbiology of flooded rice paddies. FEMS
Microbiology Reviews. 24(5), 625-645. https://doi.org/10.1016/S01686445(00)00050-4

Papademetriou, M. K., Dent, F. J., \& Herath, E. M. (Eds.). (2000). Bridging the rice yield gap in the Asia-Pacific Region (p. 222). Bangkok, Thailand: FAO Regional Office for Asia and the Pacific.

Ponnamperuma, F. N. (1972). The Chemistry of Submerged Soils. Advances in Agronomy. 24(C), 29-96. https://doi.org/ 10.1016/ S0065-2113(08)60633-1

Ratering, S., \& Schnell, S. (2016). Localization of Iron-Reducing Activity in Paddy Soil by Profile Studies. Biogeochemistry. 48(3), 341-365.

Sabir, M., Gill, M. A., Rahmatullah, T. A., \& Maqsood, M. A. (2003). Differences among rice cultivars in potassium uptake and its utilization. Pakistan Journal of Agricultural Sciences. 40, 119-121.

Sahrawat, K. (2010). Reducing Iron Toxicity in Lowland Rice with Tolerant Genotypes and Plant Nutrition. Plant Stress. 4(2), 70-75.

Sahrawat, K. L. (2000). Elemental composition of the rice plant as affected by iron toxicity under field conditions. Communications in Soil Science and Plant Analysis. 31(17-18), 28192827. https://doi.org/10.1080/ 00103620009370630

Sahrawat, K. L. (2004). Iron toxicity in wetland rice and the role of other nutrients. Journal of Plant Nutrition. 27(8), 1471-1504. https://doi.org /10.1081/PLN-200025869

Tadano, T. (1975). Devices of Rice Roots to Tolerate High Iron Concentration in Growth Media. Japan Agricultural Research Quarterly. 9, 34-39.

Tadano, T., \& Yoshida, S. (1978). Chemical changes in submerged soils and their effect on rice growth. In IRRI: Soils and Rice, 399-420.

Trolldenier, G. (1977). Mineral Nutrition and Reduction. Plant and Soil. 47, 193-202.

Trolldenier, G. (1988). Visualisation of oxidizing power of rice roots and of possible participation of bacteria in iron deposition. Zeitschrift für Pflanzenernährung und Bodenkunde. 151(2), 117-121. https://doi.org /10.1002/jpln.19881510209

Wang, J., \& Liu, Z. Y. (1992). Iron transformation in rice rhizosphere. Acta Pedologica Sinica. 29, 358-364. 
Westerman, R. L. (1990). Soil testing and plant analysis. In Soil Science Society of America Journal (3rd ed.). Soil Science Society of America, Madison, WI, USA.

Yoshida, S. (1981). Fundamental of Rice Crop Science. International Rice Research Institute, Manila, The Philippines.

Yoshida, S., Forno, D. A., Cock, J. H., \& Gomez, K. A. (1976). Laboratory manual for physiological studies of rice (3rd ed.). International Rice Research Institute, Manila, The Philippines. 